UDK 528.71

\title{
PHOTOGRAMMETRIC DOCUMENTATION OF CZECHOSLOVAK BORDER FORTIFICATIONS AT HLUČÍN-DARKOVIČKY
}

\author{
Roman Kapica $^{1}$, Dana Vrublová ${ }^{2}$, Markéta Michalusová ${ }^{3}$ \\ ${ }^{1,3}$ The Institute of Geodesy and Mine Surveying, Faculty of Mining and Geology, VSB-Technical \\ University of Ostrava, 17.listopadu 15, CZ 70833 Ostrava, Czech Republic \\ ${ }^{2}$ The Institute of Combined Studies in Most, VSB-Technical University of Ostrava, Dělnická 21, \\ Most, Czech Republic \\ E-mails: ${ }^{1}$ roman.kapica@vsb.cz (corresponding author); ${ }^{2}$ dana.vrublova@vsb.cz; \\ 3 michalusova.m@centrum.cz
}

Received 08 February 2013; accepted 16 May 2013

\begin{abstract}
The Institute of Geodesy and Mine Surveying of the Technical University Ostrava makes photogrammetric surveying of major built objects in the Moravian-Silesian region. The focus of the present study is on special monuments that form integral parts of regional history and make outstanding landmarks. Terrestrial photogrammetry was used as the surveying methods used. The primary goal of photogrammetric surveying is to identify geometric shapes and to create visualisations of objects. Photogrammetric surveying provides valuable documentary data for uses in the areas of the history of architecture and technical research as well as for renovations and advertising campaigns. Our 3D models were created by using terrestrial digital photogrammetry.
\end{abstract}

Keywords: terrestrial photogrammetry, calibration, 3D modelling, measuring, scanning.

Reference to this paper should be made as follows: Kapica, R.; Vrublová, D., Michalusová, M. 2013. Photogrammetric documentation of Czechoslovak border fortifications at Hlučín-Darkovičky, Journal of Geodesy and Cartography 39(2): 72-79.

\section{Introduction}

The Hlučín-Darkovičky fortification system is a part of the Czechoslovak Border Fortifications built in 19351938 to protect the country from the then looming threat of German invasion. Some of the determining factors that helped bring the project under way were the elongated geographic shape of the country, the locations of strategic industrial installations (in and around Ostrava and Plzeň) and the lengths of borders on the enemy states.

The border fortifications were supposed to keep major parts of the enemy forces engaged, to slow down and exhaust the invading troops, to buy the allies some time to mobilize their own armed forces and to enable a tactical retreat and prepare a counteroffensive. Inspired by France's Maginot Line, stage I and II fortresses from 1935-36 emulated their French examples. Stage III fortifications, built since 1937, also included light bunkers of domestic design and heavy fortifications to defend the major axes against threats. But the planned scope of fortifications, especially the heavy parts, could not be completed by 1938 . The border fortifications came back on track toward the end of WWII slowing down Red Army progress. Most bunkers suffered multiple damages during WWII and later by shelling and when they lost the armoured parts, served the infantry as shooting practice targets.

Czechoslovak Border Fortifications are now a unique technical monument. They consist of army barracks, ammunition stores, water supply systems (wells, pumps and storage tanks), air filtering systems, diesel generators of electric power, a telephone network, voicepipes, grenade chutes, periscope orifices and, of course, arms and gun carriages. Only parts of the equipment were installed before the fateful days of September 1938. 


\section{Description of the Hlučín-Darkovičky section of Czechoslovak border fortifications}

The fortifications at Darkovičky fall under the Silesian Museum administration along with the now renovated World War II Memorial at Hrabyně. The Darkovičky section is a remarkable and comprehensive sample of the country's fortification system.

It consists of two separate infantry cabins (MO-S 18 and MO-S 19), one light fort of type 37 A 140Z (or, 829 according to modern-day nomenclature) and one infantry bunker (MO-S 20).

MO-S 18 is a self-contained infantry cabin with the 2 nd degree resistance capacity built with a $200 \mathrm{~cm}$ thick ceiling, MO-S 19 is one degree stronger with ceiling thickness of $250 \mathrm{~cm}$ (Fig. 1). The area around and above the two forts is covered with quarry stone, earth and grass. With camouflage nets attachable to hooks near the wall tops, the forts enjoyed a perfect degree of safety against air surveillance. The defence system included ditches dug near the loopholes and anti-infantry barriers.

MO-S 19 has type 26 light machine-gun turrets and one heavy machine-gun double cupola of type
37. The exhibition also contains one unique sample of type $3647 \mathrm{~mm}$ anti-tank cannon. One type 37 bunker is located near MO-S 19 and popularly named after the acronym of the Fortification Development Authority. MO-S 20 suffered damage from the German army. All armoured pieces were forcibly removed and the fort served as infantry target practice. The reconstruction work is costly and technically challenging and can only proceed thanks to much voluntary effort (Kuchař 2007).

\section{Geodetic surveying}

Geodetic surveying was based on the object's natural control points and the polar method with free survey station was used. The measurements were made using one Leica TPS 1200 + total station with integrated GPS receiver and a scanning module. Building control points were used to lay down the scale and 3D model orientation. Clearly visible points are used in the usual process of facade surveying. But bunker facades are in fact monotonous surfaces of concrete, making it difficult to find control points. Thus the control points used were various facade defects: traces of ageing,
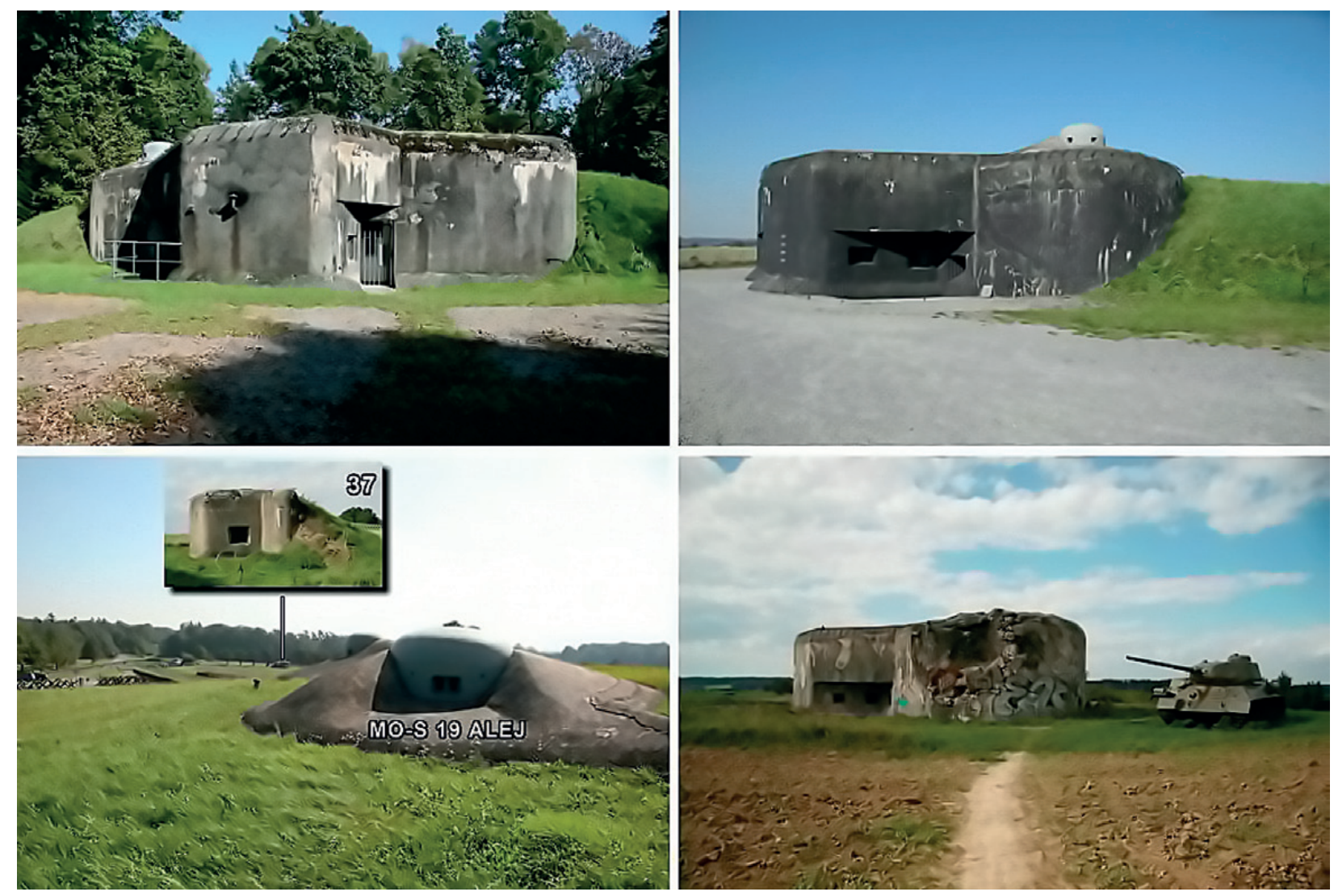

Fig. 1. Czechoslovak Border Fortifications, Hlučín-Darkovičky section. From left to right: MO-S 18 infantry cabin, MO-S 19, type 37 bunker as viewed from MO-S 19 and MO-S 20 
shooting practice or features like loophole sharp edges and entrance door edges. A set of 38 control points were identified and surveyed in prismless mode and attached to a local coordinate system. Using geodetic measurements there was alsocreated a generalized reference model for testing ofpoint cloud obtained from software PhotoModeler Scanner. The reference model consists of clearly. The geodetic and photogrammetric measurements were made in the course of August and September 2011 and 2012.

Local conditions permitting, we deployed PhotoModeler Scanner software code marks around the buildings. The code marks are automatically detected in the photos and numbered. They are quite helpful in the process of the automatic orientation of images and for high-accuracy point-by-point surveying. The code marks are available in a variety of shapes and sizes. The marks used in the present measurement process were 12-bit marks and RAD coded marks in two sizes located to mark points in double distances from the camera point. Our previous experience dictated the preference for white-on-black marks. Automatic mark detection and point cloud generation can be distorted by high-contrast shadows and their shifts between the shots. But the issue is usually solved by using a pair of synchronized cameras.

The DTM and the visualisation were created using geodetic measurements. The surveying point network was attached to the JTSK coordinate system and to the elevation system "Baltic - after Adjustment" (Bpv). The DTM and visualisation were made by means of the ATLAS DMT software and KVAS software (Sládková et al. 2011).

\section{Photogrammetric surveying}

The latest version of PhotoModeler Scanner by EOS Systems Inc., Canada, was used to create the 3D models. The software enables multiple applications like building and monument documentation, archaeological and industrial uses. The software supports tools for the evaluation of convergent and parallel surveying that enable geometric reconstructions of the objects surveyed. A visualisation can be created from the wire model by adding real textures and animations. Data exports in different formats are supported. Some of the most spectacular outputs are Google Earth and VRML files with optional backgrounds.

The following calibrated digital cameras was used for the photogrammetric surveying:

- Canon EOS 7D with EFS 18-135 mm lens, a professional-class reflex camera with 18 Mpix resolution $(5184 \times 3456 \mathrm{px})$. The camera was used to create forts' $3 \mathrm{D}$ models;

- Canon EOS 30D with EF-S 17-85 mm lens, a professional-class reflex camera with $8.2 \mathrm{Mpix}$ resolution $(3504 \times 2336 \mathrm{px})$. The camera was used during field reconnaissance.

Focus of camera was set to a specific distance according to the calibration. Due to the limited space there was used wide focal length in $18 \mathrm{~mm}$ extreme position, manual focus and image stabilization off. The non-metric digital cameras was calibrated by means of a 3D test field and by means of the PhotoModeler Scanner and MatLab software products. Both cameras were attached to tripods and manual focus at specified distances was used.

Practical tests and digital camera calibrations are made at the survey observatory of the Institute of Geodesy and Mine Surveying by means of a 3D test field consisting of 24 round marks (Fig. 2). The test field was surveyed in a local coordinate system using the 3D forward intersection method from a survey station. The station was made of concrete pillars with forced centring. Calibration results are rated by the total error and by the residual error (Gavlovský et al. 2005; Zhang 1999).

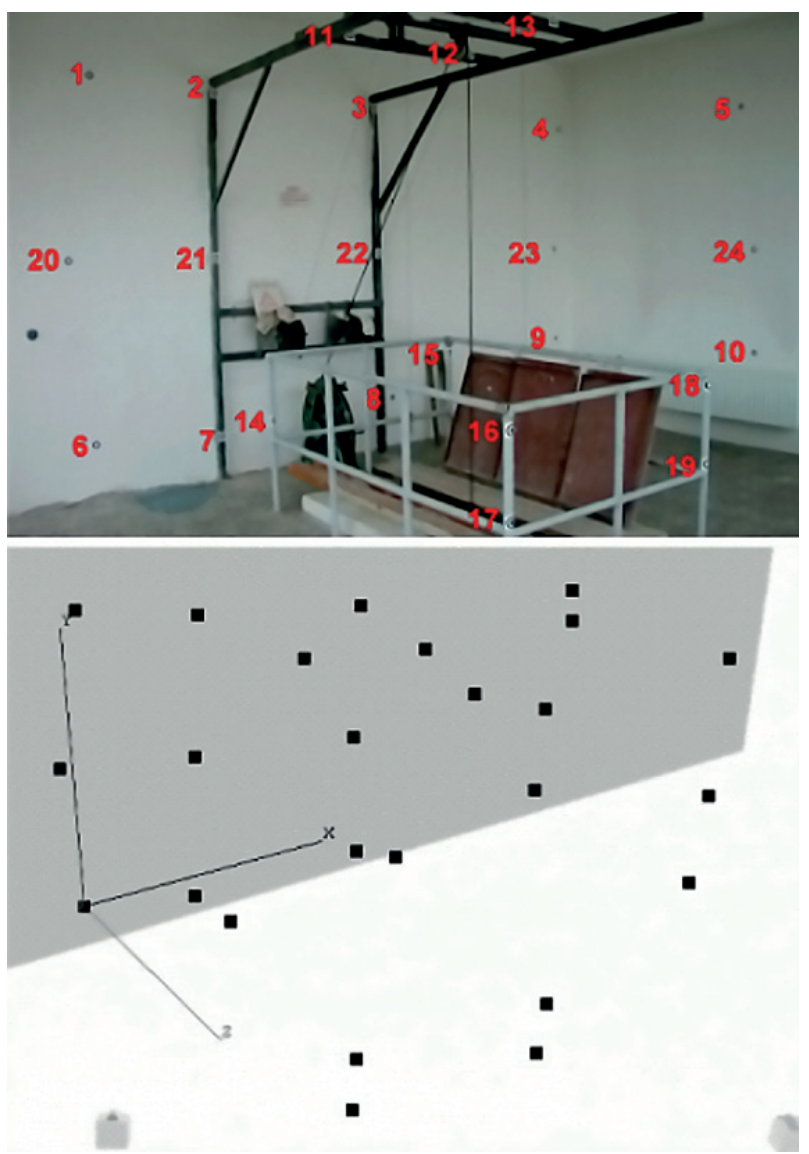

Fig. 2. 3D test IDGM field, 3D test field model 


\subsection{Convergent imaging}

Convergent imaging is applied to objects that can be unambiguously identified by means of 3D modelling tools on the basis of points, lines, planes and polygons. The imaging is usually done by completing a full circle around the object. The ideal angle of intersection is $90^{\circ}$, but line of sight angles range from $30^{\circ}$ to $150^{\circ}$ in practice. The use of the above method of imaging was limited in case of the fortifications because each object was broken down into segments. Identical points were difficult to identify on the monotonous concrete areas which made a good wire model with added textures impossible to make. Objects MO-S 19, MO-S 20 and the type 37 bunker are located in an open space while MO-S 18 is surrounded by dense vegetation. Convergent measurement was based on 23 images of MO-S 18 and on 30 images of MO-S 19, each with a $5184 \times$ 3456 pixel resolution. Average pixel size was approximately $1.5 \mathrm{~cm}$. The $3 \mathrm{D}$ viewer has layers showing camera positions, sighting lines, control point rays and the mean error ellipse (Fig. 3). Alternative textures from different camera points can be used where vegetation or other objects stand in the way.

\subsection{The normal case of close-range photogrammetry}

Parallel imaging was used to auto-generate Digital Surface Model (DSM) planes consisting of point clouds. The method was a replacement for relying on identical points that were too difficult to manually identify on the concrete surfaces. Manual mode tends to generate a smaller number of shape identifying points, but automatic measurement too, has issues to cope with, like e.g. missing parts of the model and inaccurate geometric data (signal noise). The follow-up optimizing process may lead to a partial loss of essential information.

On-site shots were made with app. 60\% overlap and a resolution of $5184 \times 3456$ pixels. With a new project created, the PhotoModeler image idealization module can be launched. Pre-idealized images show distortions toward the edges. The distortion is best seen in straight lines, which tend toward a curved appearance. The images are recalculated on the basis of camera calibration data to an ideal undistorted central projection that is suitably used to attach the textures to the $3 \mathrm{D}$ model (Fig. 4). Without this process it's not possible to create well-textured model (McGlone et al. 2004).

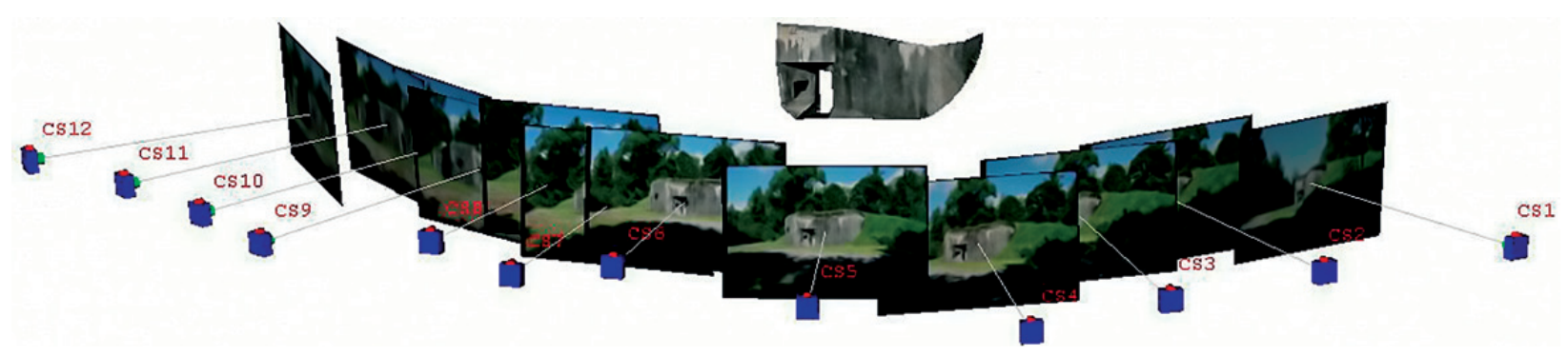

Fig. 3. MO-S 18 with camera positions for convergent imaging

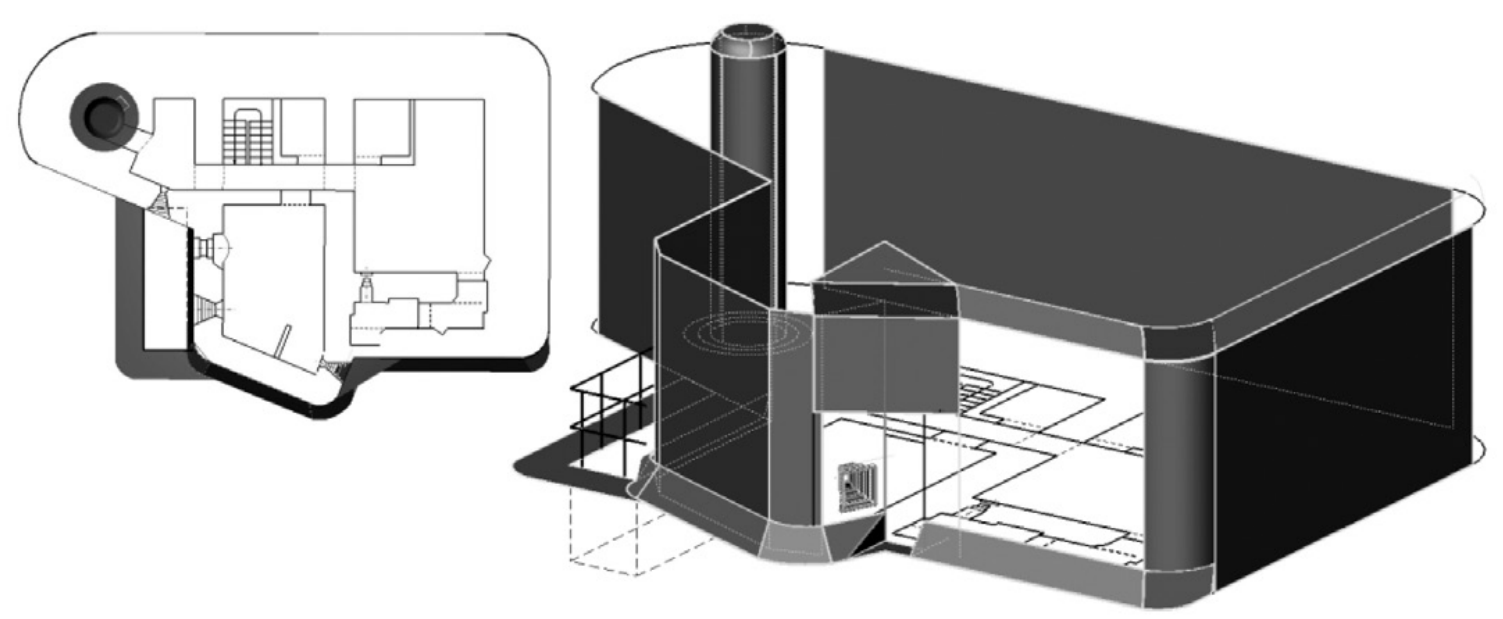

Fig. 4. 3D model MO-S 20 


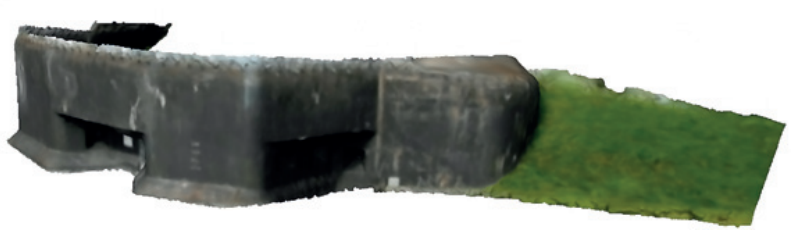

Fig. 5. 3D model MO-S 18

The DSM areas are created to define the scale and to position the object in the coordinate system. Selected point field density was $5 \mathrm{~mm}$. In the case of object MO-S 18, such point density accounts for a total point count of 1,633,616 and the number of triangles after point field clean-up is $1,844,725$ (Fig. 5).

The computation may take dozens of minutes to finish, depending on computer power and point field density. The next step was to define the size of our studied area and the size of the correlation matrix. A dense point field must be optimized further by reducing the number of triangles by $60-70 \%$ and by smoothingout the model. The level of optimization should be selected so as not to degrade the model surface (Fig. 6). The optimized triangle network was then converted to a plane (Fig. 7). 12-bit code marks from the corresponding module of the PhotoModeler Scanner software were located around the objects for the purpose of generating the DSM point cloud. Different sizes and versions of the code marks can be printed out to suit a wide variety of project scopes, small and large. Marks in the images are automatically identified and assigned target numbers. The marks allow automatic orientation of surveying images and reasonably accurate measurements of points. Photographic images for DSM projects use parallel and converging orientations. Parallel images are made at least with a $60 \%$ overlap. The point field is calculated from image pairs (Gašinec et al. 2012; Linder 2006).

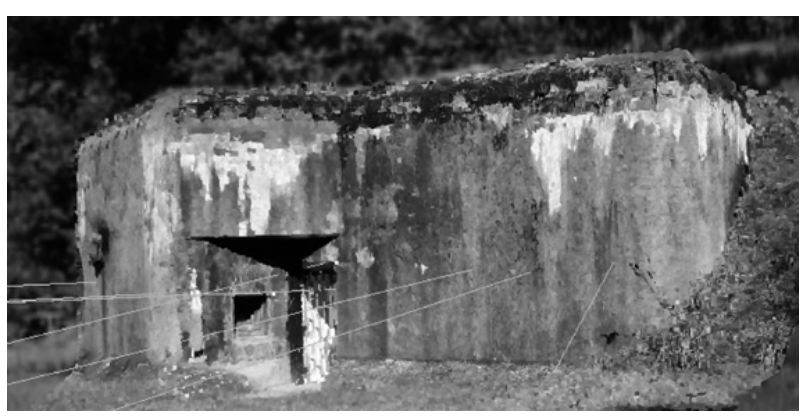

Fig. 7. MO-S 20, conversion of the triangular web to a plane
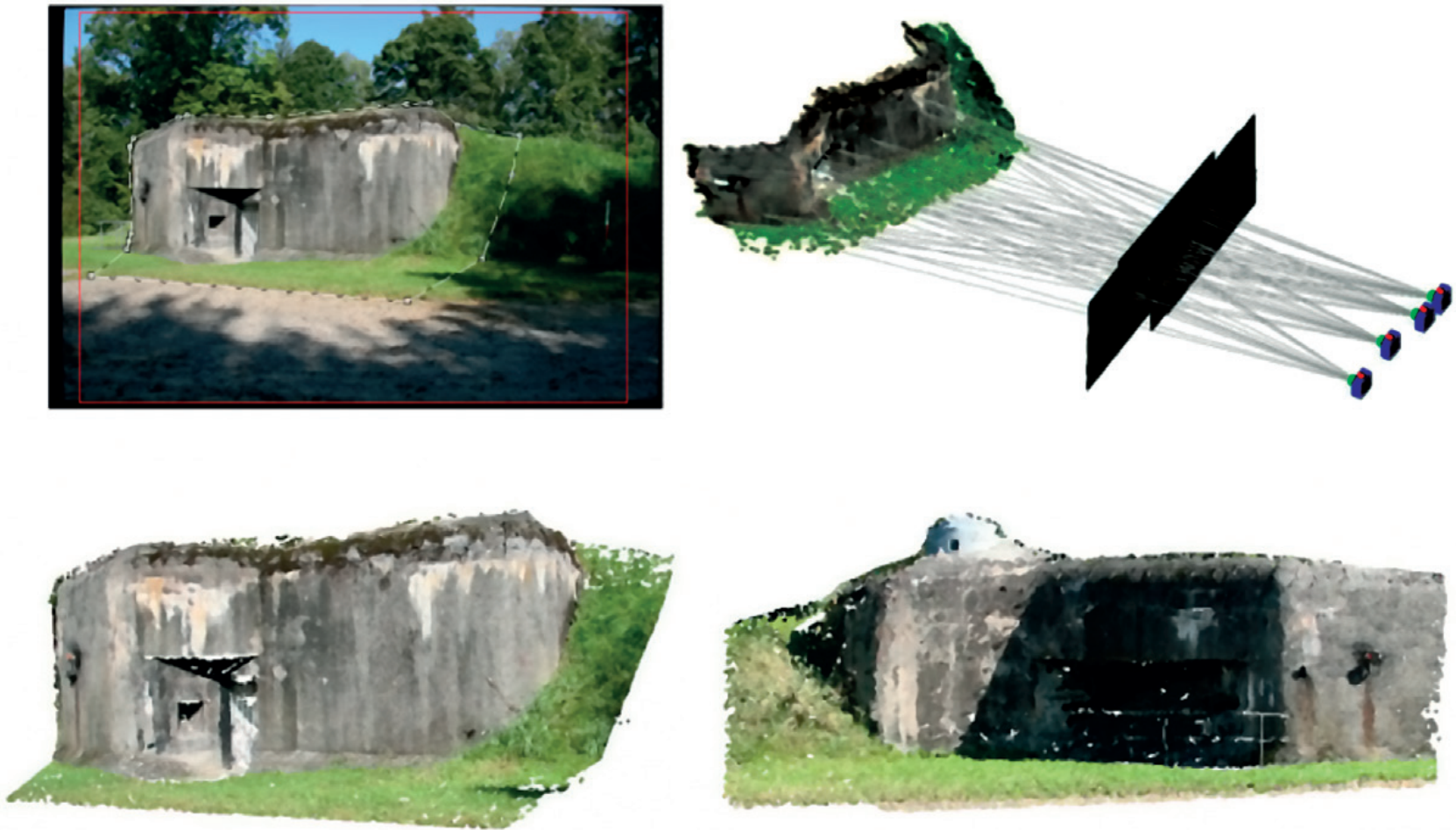

Fig. 6. From left to right: an idealized point field image, camera positions and the point cloud 


\section{Creating a 3D model}

The creation of a 3D model by means of converging and parallel imaging consists of the following basic steps:

- Make an imaging plan and arrange code marks across the terrain;

- Create the object by means of a selection of calibration parameters;

- Create an idealized photographic camera;

- Automatic identification of code marks and other identical points for image orientation;

- Define scale and attach to a coordinate system;

- Evaluate surveying images: create 3D model, attach texture fillings, create DSM planes;

- Model quality check and export;

- Create the digital terrain model (Fig. 8).

The complete model can be exported to Google Earth in KMZ or KML format (Fig. 9) and Google SketchUP (Fig. 10). The process requires three known points identified in terms of GNSS coordinates. 3D model terrain positioning is open to manual corrections by means of the application viewer or by means of auxiliary features like the "Attach to the ground" command (Kapica et al. 2011).

Google Earth enables watching the object by means of the animated fly-over feature and animation can also be enabled in the PhotoModeler software by ente- ring key images (creating the animation script). Each plane can be exported in the orthophoto corrected form containing the definition of pixels per unit density. Another useful alternative is the export in VRML format that can display the 3D model via a web interface.

Cortona 3D application is required to view objects in VRML 2.0 format. The application contains some basic features for $3 \mathrm{D}$ viewing. This way the model can be made a part of public web sites or presentations without the need to install and use the PhotoModeler. The 3D accuracy in XYZ models is around $2 \mathrm{~cm}$.

\section{Conclusions}

The development of digital photogrammetry has largely widened the options for creating technical documentations of built objects. Photogrammetric surveying makes it possible to convey built object geometric data as a 3D model. The object can be localized in topographic and altitude terms including visualisations and animated views.

For the creation of a point cloud, we used parallel images with overlap of at least $60 \%$. This imaging system is suitable for sufficiently "structured and textured" surfaces. Parallel imaging was already tested on cultural monuments affected due to mining. It isn't suitable for uniform and smooth surfaces where the

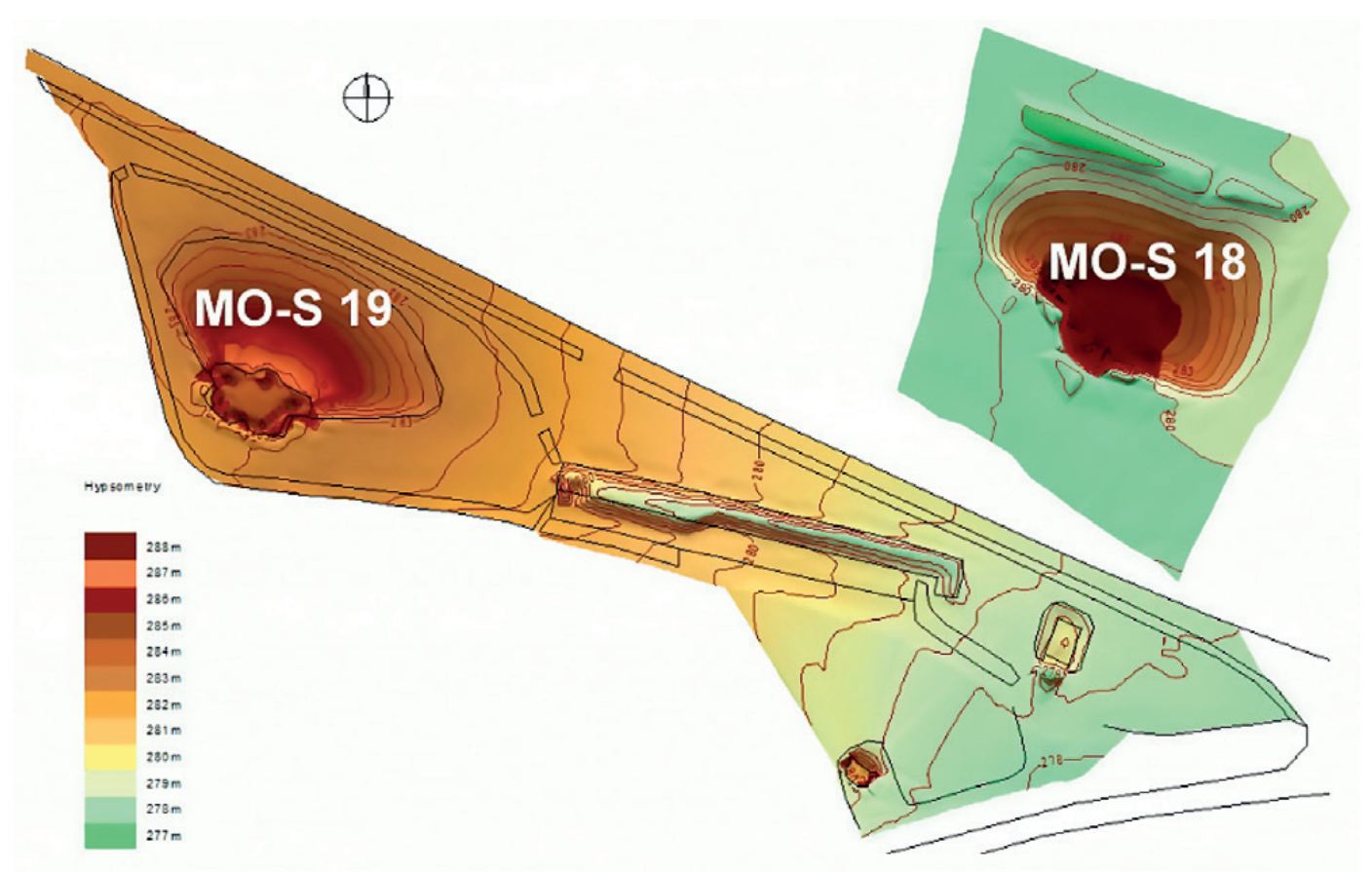

Fig. 8. MO-S 18, MO-S 19, digital terrain model 


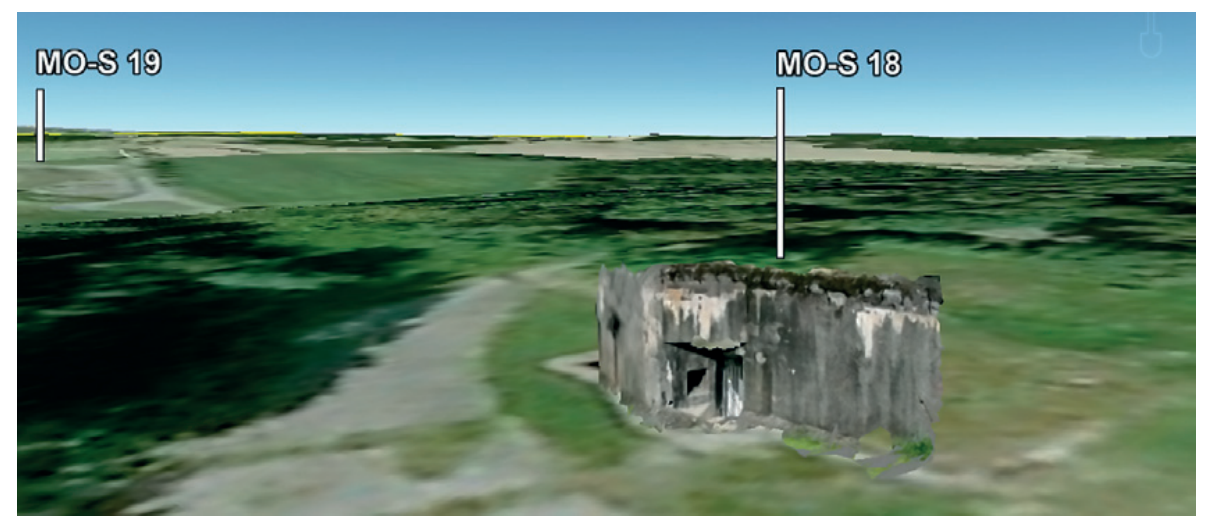

Fig. 9. MO-S 18 in Google Earth

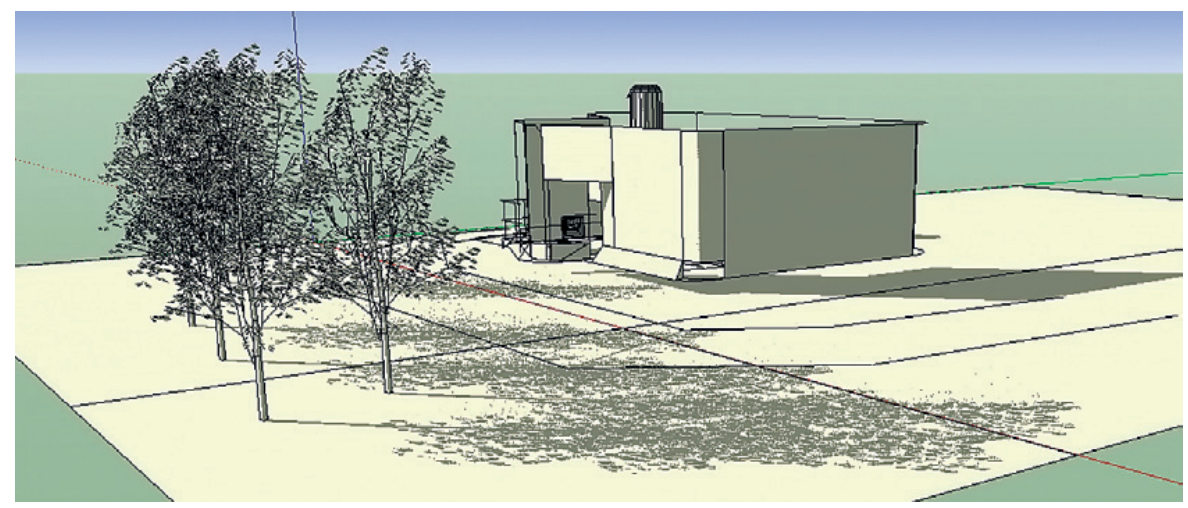

Fig. 10. MO-S 18 in Google SketchUp

signal noise gains significant values and thus prevents fidelity of the surveyed object. Photogrammetric evaluation was compared to the reference model obtained on the basis of geodetic measurements. Areas with a maximum deviation are mainly on the forts' peaks with maximum values in $5 \mathrm{~cm}$. This is due to imperfections of the model at these points, respectively small number of generated points. A few bad points and areas with uneven point field density remain in the model despite the noise reduction. When optimizing a triangular network there is a risk of model degradation. In some areas of complicated shape (loopholes and niches), there were large local declines in triangular network which reached up to the order of decimetres. These areas were cut off to avoid model distortion. Some areas created in PMS were slightly bent to the reference model. 3D laser scanning systems suggests itself for a more accurate documentation of complex surfaces. However PMS is significantly cheaper alternative.
The geodesic and photogrammetric surveying form integral parts of the documentation process of preserving monuments of high historic and architectural value. The combination of new technologies with geodesy and photogrammetry opens up unprecedented opportunities in the form of visualising monuments of history and technology.

\section{References}

Gavlovský, E.; Sojka, E.; Kapica, R.; Böhmová, D. 2005. Stereophotogrammetric measuring in the risk areas with the aid of a remotely controlled, in U. Stilla, F. Rottensteiner, S. Hinz (Eds.). Joint Workshop of ISPRS and the German Association for Pattern Recognition 'Object Extraction for 3D City Models, Road Databases and Traffic Monitoring Concepts, Algorithms, and Evaluation' (CMRT05). Vienna, Austria. 36(3/ W24). Vienna: Technical University of Vienna, 155-158. ISSN 1682-1750.

Gašinec, J; Gašincová, S.; Černota, P.; Staňková, H. 2012. Uses of terrestrial laser scanning in monitoring of ground ice within Dobšinská Ice Cave [Zastosowanie naziemnego skaningu laserowego do monitorowania lodu gruntowego $\mathrm{w}$ 
Dobszyńskiej Jaskini Lodowej], Inzynieria Mineralna 2(30): 31-42. ISSN 1640-4920.

McGlone, J. C.; Mikhail; E. M.; Bethel, J. S. 2004. Manual of Photogrammetry. Fifth edition. Maryland, USA: ASPRS (American Society for Photogrammetry and Remote Sensing). 1151 p. ISBN-10: 1570830711, ISBN-13: 978-1570830716.

Kapica, R.; Sládková, D. 2011. Photogrammetric analysis of objects in undermined territories, Geodesy and Cartography 37(02): 49-55. http://dx.doi.org/10.3846/13921541.2011.586440

Kuchař, P. 2007. Areál čs. opevnění Hlučín - Darkovičky: historie a současnost. Mgr. Aleš Horák, RETIP s. r. o., Náchod. 32 p.

Linder, W. 2006. Digital Photogrammetry: a Practical Course. Berlin, Heidelberg: Springer-Verlag. 214 p.

Sládková, D.; Kapica, R.; Vrubel, M. 2011. Global navigation satellite system (GNSS) technology for automation of surface mining, International Journal of Mining, Reclamation and Environment 25(3): 284-294.

http://dx.doi.org/10.1080/17480930.2011.608879

Zhang, Z. 1999. Flexible camera calibration by viewing a plane from unknow orientations, in International Conference on Computer Vision (ICCV'99), vol. 1, 20-27 September, 1999, Kerkyra, Corfu, Greece, 66-673. ISBN: 0-7695-0164-8. http://dx.doi.org/10.1109/ICCV.1999.791289
Roman KAPICA. Ing., Ph.D. Asst. Prof., The Institute of Geodesy and Mining Surveying, Faculty of Mining and Geology, VSB - Technical University of Ostrava, 17.listopadu 15, CZ 70833 Ostrava, Czech Republic. Ph +420 597323 302, e-mail: roman.kapica@vsb.cz

Research interests: terrestrial photogrammetry, digital photogrammetric mapping, 3D modelling and animation, cartography.

Dana VRUBLOVÁ. Ing., Ph.D. Asst. Prof., The Institute of Combined Studies in Most, Faculty of Mining and Geology, VSB-Technical University of Ostrava, Dělnická 21, Most, Czech Republic. Ph +420 597325 707, e-mail: dana.vrublova@vsb.cz

Research interests: geodesy, cartography, mine surveying.

Markéta MICHALUSOVÁ. Ing., Asst. Prof., The Institute of Geodesy and Mining Surveying, Faculty of Mining and Geology, VSB - Technical University of Ostrava, 17.listopadu 15, CZ 70833 Ostrava, Czech Republic. Ph +420 597323 302, e-mail: michalusova.m@centrum.cz

Research interests: geodesy, cartography, mine surveying. 